\title{
Distinct Specific Status of the Korean Brown Frog, Rana amurensis coreana (Amphibia: Ranidae)
}

\author{
Jae-Young Song ${ }^{1 *}$, Masafumi Matsui ${ }^{2}$, Kyu-Hoi Chung ${ }^{1}$, \\ Hong-Shik $\mathrm{Oh}^{3}$ and Wenge Zhao ${ }^{4}$ \\ ${ }^{1}$ Department of Biology, Kyonggi University, Suwon, 443-760 Korea \\ ${ }^{2}$ Graduate School of Human and Environmental Studies, Kyoto University, \\ Kyoto 606-8501, Japan \\ ${ }^{3}$ Educational Research Institute, Department of Science Education, \\ Cheju National University, Jeju 690-756, Korea \\ ${ }^{4}$ Department of Biology, Harbin Normal University, Harbin 150080, China
}

\begin{abstract}
We used morphological and genetic data to assess the taxonomic status of Rana amurensis coreana and R. a. amurensis. Morphological comparisons revealed these two subspecies to be different from each other in size of body, nature of tubercles on dorsal stripe, degree of development in toe webbing, and condition of lateral spots of trunk. They were also different in sequence of mitochondrial 16S rRNA gene, with genetic distance as large as those observed among different species of brown frogs. Therefore, Korean populations previously considered a subspecies of $R$. amurensis should be regarded as a distinct species $(=R$. coreana).
\end{abstract}

Key words: mitochondrial 16S rRNA, morphology, taxonomy, phylogeny, China, Russia

\section{INTRODUCTION}

Rana is the largest genus of ranids, with approximately 240 species (Frost, 2004). In Korea, six species of Rana have been recorded: three brown frogs $(R$. amurensis coreana, $R$. dybowskii, $R$. huanrenensis), two pond frogs ( $R$. nigromaculata, $R$. plancyi chosenica) and one wrinkle frog (R. rugosa) (Kang and Yoon, 1975; Zhao and Adler, 1993; Sengoku et al., 1996; Maeda and Matsui 1999, Yang et al., 2000; Yang et al., 2001). Among these, species of brown frogs are very difficult to identify because they are morphologically similar (Nakamura and Uéno, 1963). Rana amurensis coreana is known only from South Korea, and was originally described as a subspecies of European $R$. temporaria (Okada, 1928). Later, it was moved on morphological grounds to a subspecies of $R$. amurensis, a species occurring Russian Far East and northeastern China (Shannon, 1956). Since Shannon's review, this taxonomic arrangement has been widely accepted (Dixon, 1956; Yang and Yu, 1978).

Recently, mitochondrial DNA (mtDNA) sequences have been is widely used to estimate phylogenetic relationships of various organisms (e.g., Brown et al., 1982; Smith and Patton, 1991; Moritz et al., 1992: Tan and Wake, 1995; Tanaka-Uedo, 1998). Mitochondrial DNA has a smaller genome size (15.0-20.0kb) and evolves more rapidly than the nuclear DNA (perhaps 5-10 times faster than a typical single-copy nuclear DNA) and is maternally inherited. For

\footnotetext{
${ }^{*}$ Corresponding author. Phone: +82-31-249-9641; Fax : +82-31-251-4721; E-mail: song@seoul.korea.com
}

solving phylogenetic problems at the level of species, genus or family, 16S rRNA gene has been used among mtDNA genes. Preliminary analyses of ranid frogs, including $R$. $a$. coreana (Song et al., 2003) indicate that $16 \mathrm{~S}$ may be applied to solve relationships of closely related brown frogs.

The aim of this study is to clarify phylogenetic and taxonomic relationships of $R$. a. coreana with the nominotypical subspecies from outside of Korea using concordant morphological and genetic sequence data of $16 \mathrm{~S}$ rRNA.

\section{MATERIALS AND METHODS}

\section{Morphological analysis}

We studied a total of 36 specimens of Rana amurensis ( $R$. a. amurensis: $\mathrm{n}=16 ; R$. a. coreana: $\mathrm{n}=20$ ) and 50 specimens of three brown frog species $(R$. tsushimensis: $\mathrm{n}=14 ; R$. dybowskii: $\mathrm{n}=16 ; R$. huanrenensis: $\mathrm{n}=20$ ) for comparisons. These brown frogs were collected from different areas in Korea, China, and Japan (Table 1). All specimens were anesthetized with chloroform, dissected for tissue samples, and then fixed in $10 \%$ formalin.

These specimens and tissues are kept in $70 \%$ ethanol, in the Ecological Laboratory of Kyonggi University (KUEL).

Examinations of qualitative characteristics were done using a stereoscopic microscope (SZ-ST, Olympus Co.) and a CCD color camera (No. IK-642K, Toshiba Co.). We analyzed following morphological characteristics: (1) shape of toe and finger tips; (2) marking on lower jaw; (3) line of upper lip; (4) size of tympanum; (5) degree of development in toe webbing; (6) degree of development of vomerine teeth series; (7) pattern of dorsolateral fold; (8) shape of snout; (9) length of hindlimb; (10) tubercules on dorsum. Terminology followed Kang and Yoon (1975), and Maeda and Matsui (1999).

For morphometric analysis, the method modified from Matsui (1984) was used, and measurements were made with digital calipers to $0.1 \mathrm{~mm}$ for the following 15 characters: (1) snout-vent length (SVL); (2) head length (HL); (3) nostril-eyelid length (N-EL); (4) 
Table 1. Collection localities and sample size of brown frogs and outgroup species used in this study

\begin{tabular}{llcc}
\hline \multirow{2}{*}{ Species } & Locality & \multicolumn{2}{c}{ Sample size } \\
\cline { 2 - 3 } R. a. amurensis & Tonghe, Heilongjiang Province, China & Male & Female \\
& Pilevskoskovo, Sakhalin, Russia & 3 & 3 \\
& Aniva, Sakhalin, Russia & 3 & 1 \\
R. a. coreana & Mt. Gwangkyo, Paldal-Gu, Suwon, South Korea & 3 & 2 \\
& Daecheon, Boryeong, Chungcheongnam-do, South Korea & 4 & 5 \\
R. huanrenensis & Mokgeri, Uhmjeong-Myeon, Chungju, South Korea & 4 & 2 \\
R. dybowskii & Mt. Seorak, Inje-Gun, Gangwan-do, South Korea & 3 & 5 \\
R. tsushimensis & Mupo, Daehongdan-Gun, Ryanggang-do, North Korea & 15 & 6 \\
R. chensinensis & Keiher, Daxinganling, Heilongjiang Province, China & 3 & 3 \\
R. catesbeiana & Gangwha bridge, Gimpo, Gyeonggi-do, Korea & 4 & 6 \\
\hline
\end{tabular}

(A)

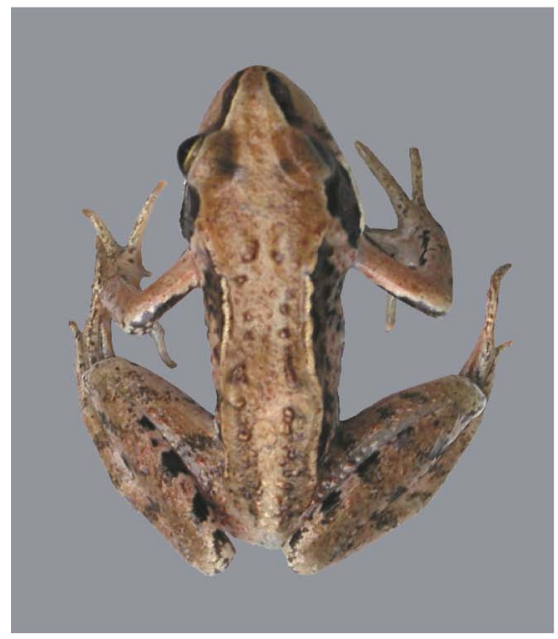

(C)

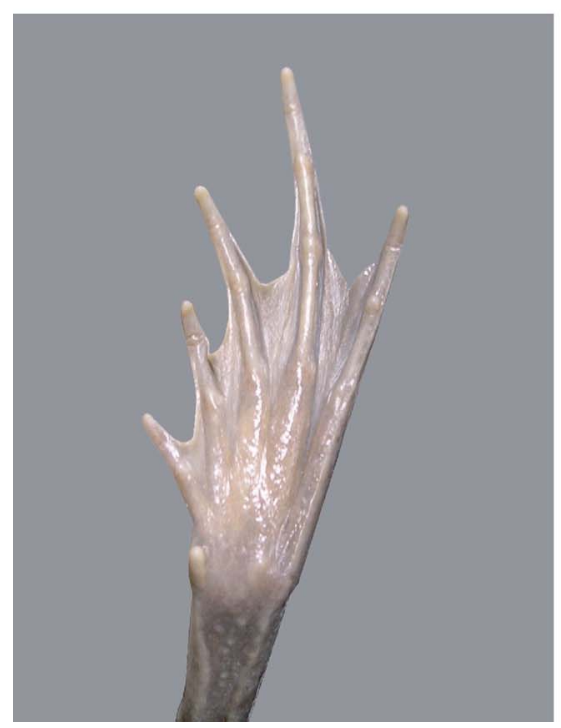

(B)

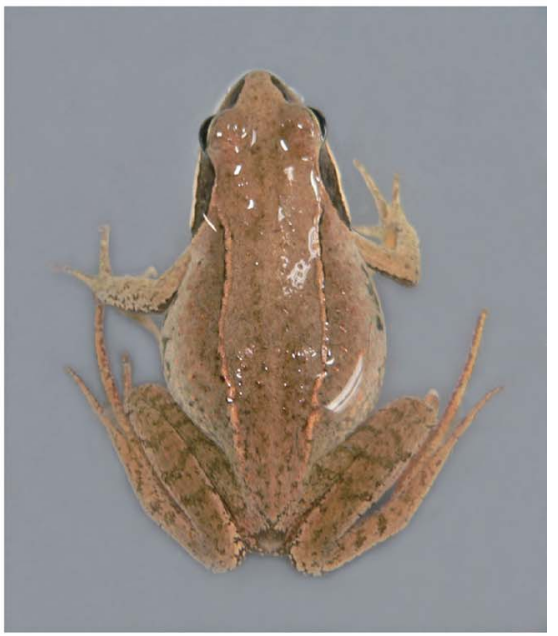

(D)

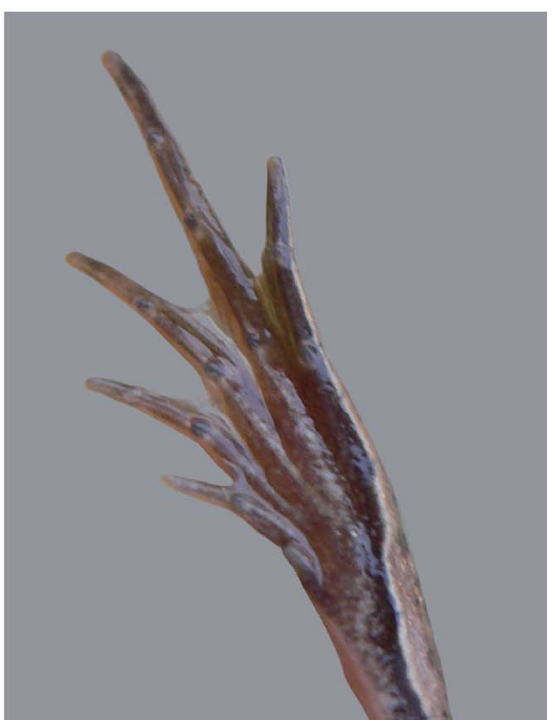

Fig. 1. Dorsal surface of R. a. amurensis (A) and R. a. coreana, and Plantar surface of left foot of R. a. amurensis (C) and R. a. coreana (D). 
snout length (SL); (5) eye length (EL); (6) tympanum-eye length (T$\mathrm{EL})$; (7) tympanum diameter (TD); (8) head width (HW); (9) internarial distance (IND); (10) interorbital distance (IOD); (11) radioulna length (RUL); (12) tibia length (TL); (13) foot length (FL); (14) thigh length (THIGH); (15) inner metatarsal tubercle length (IMTL).

Statistic analyses were performed by SPSS 11.5 software package (Statistical Package of the Social Science). For morphometric comparisons, we applied t-test(ANOVA and Tukey HSD) for absolute size, and Mann-Whitney's $U$ tests for ratios. We also performed Canonical Discriminant Analyes (CANDISC) to examine overall size and shape differences.

\section{Genetic analysis}

In order to examine phylogenetic relationships among Korean brown frogs, we obtained partial sequences of 16S rRNA (ca. 420bp) from seven species of Rana. Additionally, four specimens (Graduate School of Human and Environmental Studies, Kyoto University (=KUHE) $11639,11640,33644$, and 33647 ) of $R$. a. amurensis from Russia were sequenced. We selected $R$. catesbeiana as an outgroup (Table 1).

Total DNA was extracted from frozen $(-70 \mathrm{C})$ tissue samples of the hindlimb muscle, using an extraction buffer $(150 \mathrm{mM} \mathrm{Nacl}, 10$ $\mathrm{mM}$ Tris- $\mathrm{HCl}$ ( $\mathrm{pH} 8.0), 10 \mathrm{mM}$ EDTA, $1 \%$ sodium dodecyl sulfate), proteinase $\mathrm{K}$, and phenol. Amplification were done by the polymerase chain reaction (PCR), using the primers 16S1F (5'-GAGGTCCAGCCTGCCCAG-3') and 16S1R (5'-CCCTGATACCAACATCGAG-3') (Song et al., 2003). The amplified fragments were sequenced in an automated DNA sequencer (ABI PRISM 3100) using the PCR primers and following the manufacturer's instructions.

Sequences were aligned using CLUSTAL W 1.4. The nucleotide sequences of $16 S$ were combined into a single data set of 414-bp. We used Maximum Likelihood (ML) to estimate phylogeny in PAUP* 4.0b(Swofford, 1998). Heuristic searches were performed using 100 replicates of a stepwise addition of taxa, and Bootstrapping (Felsenstein, 1985) was employed to assess relative nodal support (100 replicates). Pairwise comparisons of corrected sequence divergences [Kimura-2 parameter (K2p) distances (Kimura, 1980)] were also made with PAUP. In these analyses, ratio of transition: transversion bias was equally weighted.

\section{RESULTS}

\section{Morphological analysis}

Our examination of color variation in $R$. amurensis revealed patterns fixed color difference between populations. Rana a. amurensis had two dorsal stripes having tubercles each with a black spot, whereas $R$. $a$. coreana had two dorsal stripes with black spots but not with tubercles. Rana a. amurensis has many tubercles on dorsum and ventrum, whereas $R$. a. coreana has smooth skin dorsally and ventrally (Fig. 1). Similarly, sides of body are rough in $R$. a. amurensis, but are smooth in $R$. a. coreana. Rana a. amurensis has dark brown or red spots on sides of body, that are absent in $R$. a. coreana. Further, small tubercles on ventral side of the thigh are more developed in $R$. a. amurensis than in $R$. a. coreana. Toe webbing of $R$. a. amurensis $\left(\left|1 \frac{1 / 4}{4}-3 / 4\right|\left|3 / 4-2^{1 / 4}\right|||^{3 / 4} 1^{3 / 4} \mid \mathrm{V} 13 / 4-1 \frac{1}{4} \mathrm{~V}\right)$ is much more developed than in $R$. a. coreana (| 23/4-23/4 I| 21/4-13/4 III 13/4-13/4 IV $23 / 4-13 / 4$ V).

Body size in male $R$. a. coreana (mean $=38.4 \pm 3.9 \mathrm{~mm}$ $\mathrm{SD})$ was significantly smaller than $R$. a. amurensis (53.3 $\pm 5.7 \mathrm{~mm}$ SD; t-test, $\mathrm{p}<0.05)$ but female $R$. a. coreana $(44.4 \pm 3.6 \mathrm{~mm}$ SD) were statistically indistinguishable ( $p>0.05$ ) from females of $R$. a. amurensis (45.0 $\pm 8.7 \mathrm{~mm}$ SD). This may probably be due to small sample size of females.

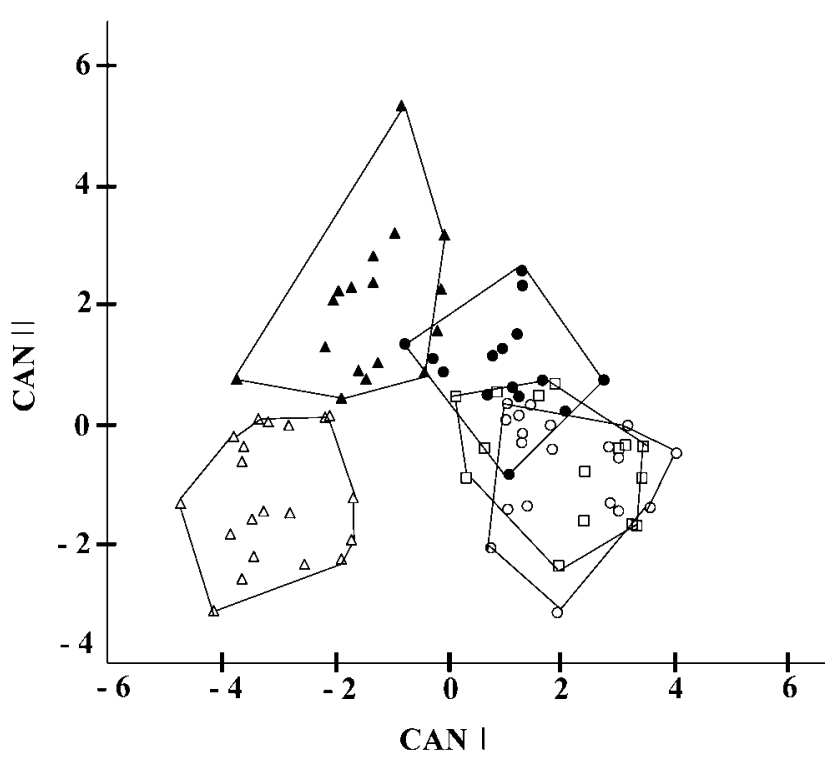

Fig. 2. Plot of first against second canonical variates for brown frogs compared. R. a. coreana (open triangles); R. a. amurensis (closed triangles); $R$. tsushimensis (open squares); $R$. dybowskii (closed circles); R. huanrenensis (open circles).

Table 2. Pairwise Kimura's (1980) distance among brown frogs (1-8) and an outgroup (9). 1: $R$. dybowskii (S. Korea); 2: R. dybowskii (N. Korea); 3: R. huanrenensis (S. Korea); 4: R. chensinensis (China); 5: R. tsushimensis (Japan); 6: R. a. coreana (S. Korea); 7: R. a. amurensis (China); 8: R. a. amurensis (Russia); 9: R.catesbeiana.

\begin{tabular}{lllllllll}
\hline & 1 & 2 & 3 & 4 & 5 & 6 & 7 & 8 \\
\hline 2 & 0.0000 & - & & & & & & \\
3 & 0.0380 & 0.0380 & - & & & & & \\
4 & 0.0516 & 0.0516 & 0.0487 & - & & & & \\
5 & 0.0647 & 0.0646 & 0.0672 & 0.0698 & - & & & \\
6 & 0.0835 & 0.0835 & 0.0838 & 0.0867 & 0.0842 & - & & \\
7 & 0.0948 & 0.0948 & 0.0950 & 0.0896 & 0.0786 & 0.0458 & - & \\
8 & 0.0948 & 0.0948 & 0.0950 & 0.0896 & 0.0786 & 0.0458 & 0.0000 & - \\
9 & 0.1917 & 0.1917 & 0.1901 & 0.1969 & 0.1740 & 0.1645 & 0.1670 & 0.1670 \\
\hline
\end{tabular}


When compared with other species, $R$. a. coreana was similar with $R$. tsushimensis $(35.9 \pm 3.8 \mathrm{~mm})$ but was smaller than $R$. huanrenensis $(48.1 \pm 3.3 \mathrm{~mm})$ and $R$. dybowskii $(59.5 \pm 9.6 \mathrm{~mm})$ (t-test, $\mathrm{p}<0.05)$.

The post-hoc analysis by the Tukey HSD test showed that the mean foot length of $R$. a. coreana was relatively long compared with that of the other species, and ANOVA revealed a significant difference in the relative foot length between all brown frogs $(F=7.916, P<0.05)$. The ratio of foot length to tibia length $(=100 \mathrm{FL} / \mathrm{TL})$ was significantly larger in $R$. a. coreana $(119.6 \pm 4.8 \%)$ than in $R$. a. amurensis $(114.7 \pm 5.7 \%)$ and other species compared ( $R$. tsushimen-

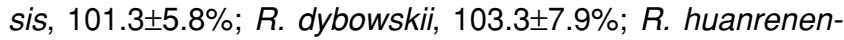
sis, $104.8 \pm 5.9 \%)(\mathrm{U}=87.0, \mathrm{p}=0.20)$.

As a result of CANDISC, nine characters (N-EL, EL, TEL, TD, HW, IND, RUL, TL, FL and IMTL) revealed to be useful in differentiating each brown frog taxon. The each eigenvalue and the percent variance accounted for 4.606 and $56.2 \%$ (I), 1.539 and $18.8 \%$ (II), 1.294 and 15.8 (III), and 0.756 and 9.2 (IV). In the first two axes, $R$. dybowskii, $R$. huanrenensis and $R$. tsushimensis largely overalpped, but each of $R$. a. amurensis and $R$. a. coreana did not overlap with other species (Fig. 2).

\section{Genetic analysis}

Of the 414 nucleotide positions aligned, 93 were variable. The gene sequence was completely identical between Chinese and Russian $R$. a. amurensis. By contrast, $R$. a. coreana was very remote from these populations of $R$. a. amurensis with large $\mathrm{K} 2 \mathrm{p}$ distance of 0.0458 , which value was similar to those observed $(0.0380-0.0698)$ among different species of other brown frogs ( $R$. chensinensis, $R$. huanrenensis, $R$. dybowskii, and $R$. tsushimensis) (Table 2).

In the maximum-likelihood tree $(-\operatorname{lnL}=1241.04706)$, two

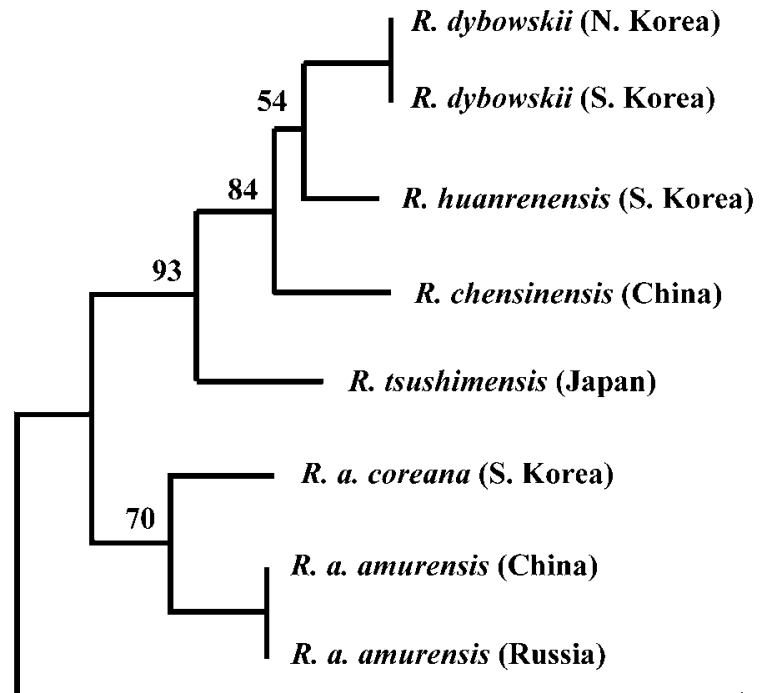

R. catesbeiana

\subsection{5 substitutions/site}

Fig. 3. $A M L$ tree for brown frogs compared. Numbers on nodes indicate bootstrap proportions.

main clades were recognized within brown frogs (Fig. 3). One main clade, supported by $70 \%$ iterations, contained $R$. a. amurensis and $R$. a. coreana, and another, suported by 93\% iterations, included $R$. dybowskii, $R$. tsushimensis, $R$. huanrenensis, and $R$. chensinensis. In the latter main clade, however, relationships among taxa included were not resolved except that $R$. tsushimensis was sister to the remaining three taxa.

\section{DISCUSSION}

Recognition of more than one species of brown frogs in Korea dates back to Stejneger (1907), who identified a Korean brown frog in the collection of Philadelphia Academy of Sciences from Chemulpo as $R$. japonica, and also recorded $R$. amurensis from the same locality. Thereafter, Okada (1928) recognized three subspecies of $R$. temporaria from Korea, and described one of them as a new taxon $R$. temporaria coreana.

Later, Shannon (1956) changed the name of this taxon to $R$. amurensis coreana. His idenfication was made on the bases of (1) the lack of vocal sacs in male Korean frog, which is possessed by male $R$. temporaria, and (2) morphologically close similarity of Korean frog with Russian $R$. amurensis. However, he (Shannon, 1956) did not give morphological criteria adequate to differentiate these two subspecies. Since then, no detailed taxonomic study was made to reassess relationships of the two subspecies of $R$. amurensis. Thus, Korean authors have treated this frog variously as a distinct subspecies or without discriminating subspecies in biological works from many aspects (Kang and Yoon, 1975; Yang et al., 2001).

As clearly shown by our genetic results, the two "subspecies" of $R$. amurensis are monophyletic and at the same time they are genetically divergent to the same degree as observed among other full species of Brown frogs. Rana a. amurensis has a very wide range of distribution, but is known to be extensively uniform genetically (Tanaka-Ueno et al., 1998). Thus, presence of a subspecies only in South Korea is biogeographically unlikely.

Our morphological analyses also resulted in clear distinction of the two "subspecies" of $R$. amurensis. As shown in the result of CANDISC, $R$. a. coreana differed morphologically from $R$. a. amurensis with the magnitude larger than that observed between two good species, $R$. dybowskii and $R$. huanrenensis.

We conclude from both genetic and morphological evidence that the Korean brown frog should be elevated to the status of full species. The correct specific epithet for this species is Rana coreana (Korean name, Hankook-sangaeguri).

\section{ACKNOWLEDGMENTS}

We are grateful to Dr. Han, Sang-Hoon (National Parks Authority, Korea) for assistance to obtain $R$. dybowskii specimens from North Korea, and Prof. Piao, Ren-Zhu (Institute of Wildlife of Heilongjiang Province, China) for helping with collection, and Prof. Xiao, Xiang-Hong (Northeast Forestry University, Heilongjiang Province, China) for their kind assistance in providing specimens of R. a. amurensis.

\section{REFERENCES}

Brown WM, Prager EM, Wang A, Wilson AC (1982) Mitochondrial DNA sequence of primates: Tempo and mode of evolution. $J$ Mol Evol 18: 225-239

Dixon JR (1956) A collection of amphibians and reptiles from west 
central Korea. Herpetologica 12: 50-56

Felsenstein J (1985) Confidence limits on phylogenies: an approach using the bootstrap. Evolution 39: 783-791

Frost DR (2004) Amphibian Species of the World: an Online Reference. Version 3.0 (22 August, 2004). Electronic Database accessible at http://research.amnh.org/herpetology/amphibia/ index.html. American Museum of Natural History, New York

Kang YS, Yoon IB (1975) Illustrated Encyclopedia of Fauna and Flora of Korea Vol 17 Amphibia, Reptila. The Korean Ministry of Education, Seoul

Kimura M (1980) A simple method for esticating evolutionary rates of base substitutions through comparative studies of nucleotide sequences. J Mol Evol 16: 111-120

Maeda N, Matsui M (1999) Frogs and Toads of Japan, Revised Edition. Bun-Ichi Sogo Shuppan, Tokyo

Matsui M (1984) Morphometic variation analyses and revision of the Japanese toads (Genus Bufo, Bufonidae). Contrib Biol Lab Kyoto Univ 26: 209-428

Moritz C, Schneider GJ, Wake DB (1992) Evolutionary relationships within the Ensatina eschscholtzii complex conform the ring species interpretation. Syst Biol 41: 273-291

Nakamura K, Uéno SI (1963) Japanese Reptiles and Amphibians in Colour. Hoikusha, Osaka

Okada Y (1928) Frogs in Korea. J Chosen Nat Hist Soc 6: 15-46

Sengoku S, Hikida T, Matsui M, Nakaya K et al. (1996) The Encyclopedia of Animals in Japan 5, Amphibians, Reptiles, Chondrichthyes. Heibonsha, Tokyo

Shannon FA (1956) The reptiles and amphibians of Korea. Herpetologica 12: 22-49
Smith MF, Patton JL (1991) Variation in mitochondrial cytochrome b sequence in natural populations of South American akodontine rodents (Muridae: Sigmodontinae). Mol Biol Evol 8: 85-103

Song JY, Yoon BS, Oh HS, Chung KH (2003) Genetic diversity of Rana amurensis (Amphibia: Ranidae), based on mitochondrial 16S rDNA gene sequences. Kor J Environ Biol 21: 45-51

Stejneger L (1907) Herpetology of Japan and adjacent territory. Bull US Nat Mus 58: 1-577

Swofford DL (1998) Phylogenetic analysis using parsimony, Version 4.0beta version. Laboratory of Molecular Systematics Smithsonian Institution, Washington

Tan AM, Wake DB (1995) MtDNA phylogeography of the California newt, Taricha torosa (Caudata, Salamandridae). Mol Phyl Evol 4: 383-394

Tanaka-Ueno T, Matsui M, Sato T, Takenaka S, Takenaka O (1998) Local population differentiation and phylogenetic relationships of Russian brown frog, Rana amurensis inferred by mitochondrial cytochrome b gene sequences (Amphibia, Ranidae). Jpn J Herpetol 17: 91-97

Yang SY, Yu CH (1978) Check List of Korean Amphibians. Inha University IIR 5: 81-90

Yang SY, Kim JB, Min MS, Suh JH, Kang YJ (2001) Monograph of Korean Amphibia. Academic Press, Seoul

Yang SY, Kim JB, Min MS, Suh JH, Kang YJ, Matsui M, Fei L (2000) First record of a brown frog Rana huanrenensis (Family Ranidae) from Korea. Kor J Biol Sci 4: 45-50

Zhao EM, Adler K (1993) Herpetology of China. Soc Stud Amphib Rept, Oxford

(Received May 31, 2005 / Accepted November 22, 2005)

Appendix 1. Nucleotide sequence alignment of the mitochondrial $16 \mathrm{~S}$ rRNA genes (414bp) in brown frogs and an outgroup, $R$. catesbeiana.

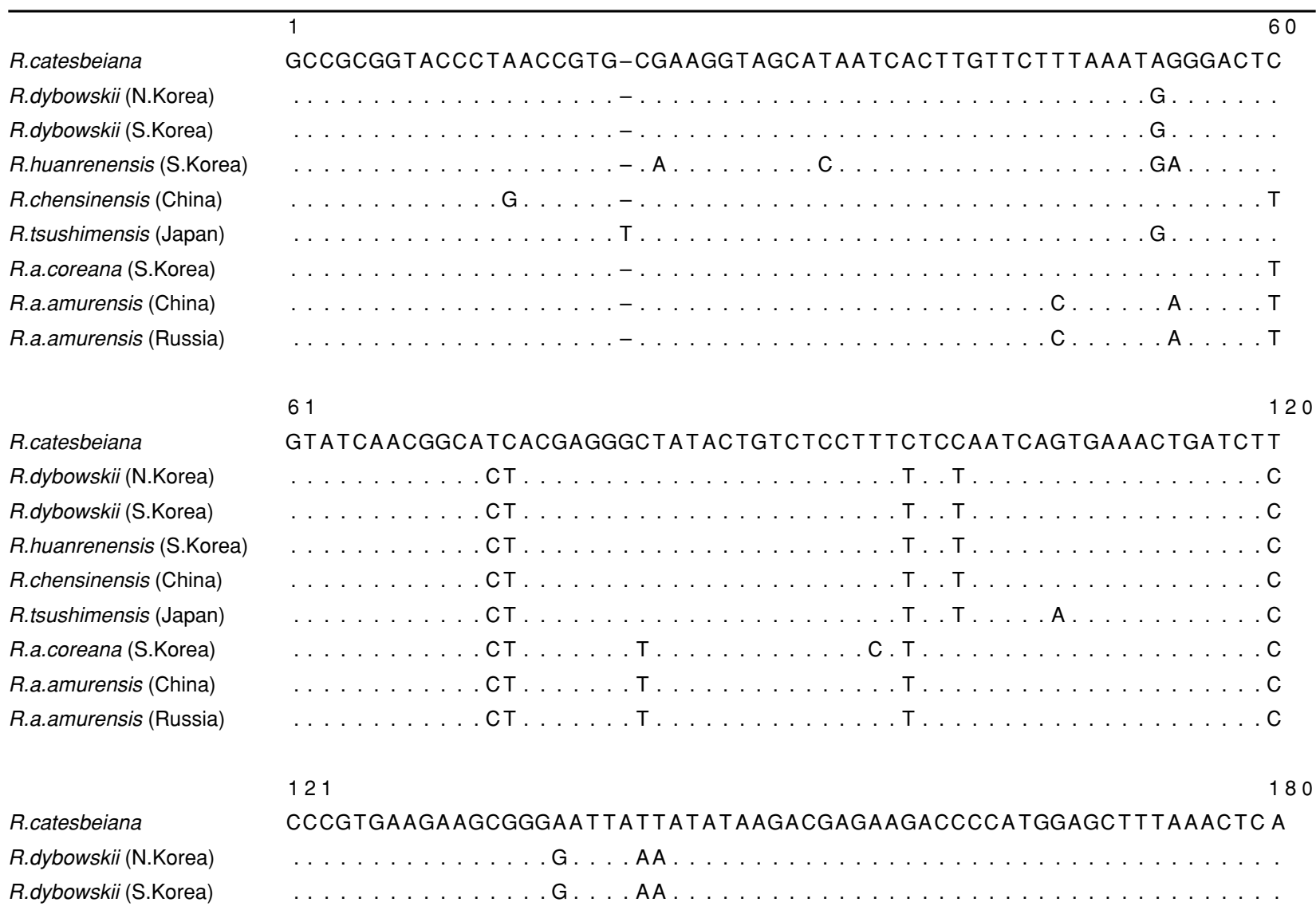


Appendix 1. Continued

\begin{tabular}{|c|c|}
\hline a) & 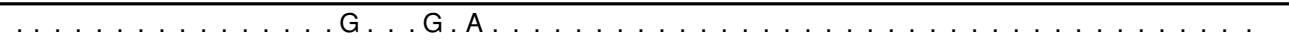 \\
\hline R.chensinensis (China) & 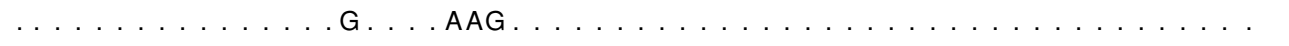 \\
\hline R.tsushimensis (Japan) & $\ldots \ldots \ldots \ldots \ldots \ldots \ldots \ldots \ldots \ldots$ \\
\hline R.a.coreana (S.Korea) & 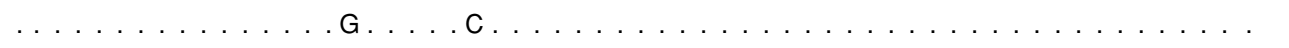 \\
\hline R.a.amurensis (China) & 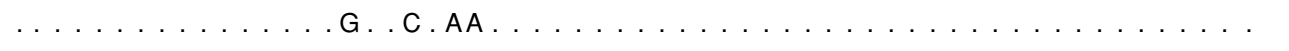 \\
\hline \multirow[t]{2}{*}{ R.a.amurensis (Russia) } & 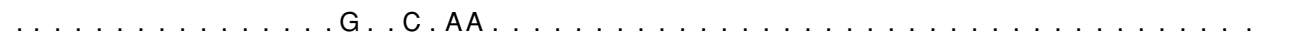 \\
\hline & 181 \\
\hline R.catesbeiana & АTATATATTTCTACGCACTTATATCACTATTAGCCTAA-GAAAACTATGTATTAGTTTTA \\
\hline R.dybowskii (N.Korea) & 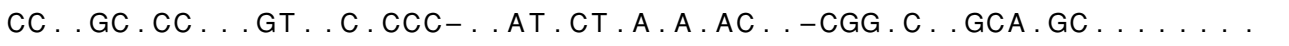 \\
\hline R.dybowskii (S.Korea) & $C C \ldots G C . C C \ldots G T \ldots C \cdot C C C-\ldots A T \cdot C T \cdot A \cdot A \cdot A C \ldots-C G G . C \ldots G C A \cdot G C \ldots$ \\
\hline R.huanrenensis (S.Korea) & 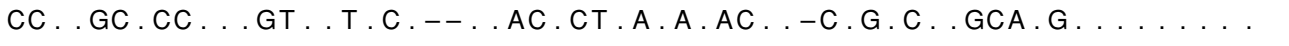 \\
\hline R.chensinensis (China) & 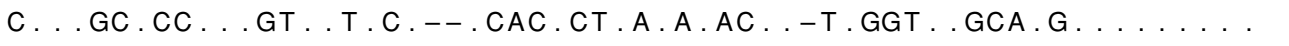 \\
\hline R.tsushimensis (Japan) & $C \ldots G C, C C \ldots G T \ldots C . C .----A C \cdot A C A \ldots A \cdot A C \ldots G T \cdot G T C \ldots G C A \ldots$ \\
\hline R.a.coreana (S.Korea) &  \\
\hline R.a.amurensis (China) & 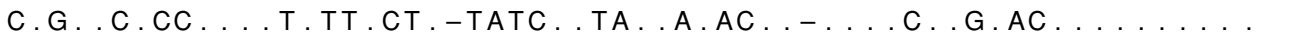 \\
\hline \multirow[t]{2}{*}{ R.a.amurensis (Russia) } & 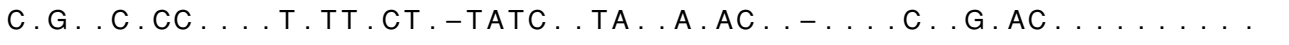 \\
\hline & 241 \\
\hline R.catesbeiana & GGTTGGGGGGACCGCGGAGAAAAAATTAACCTCCACGACAAATAGGCCAACGCCTTTAT C \\
\hline R.dybowskii (N.Korea) & 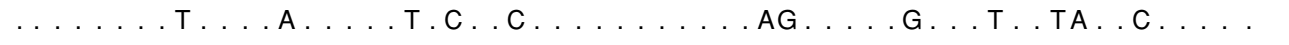 \\
\hline R.dybowskii (S.Korea) & $\ldots \ldots$. . . . . . T C . C . . . . . . . . TA . . . \\
\hline R.huanrenensis (S.Korea) & 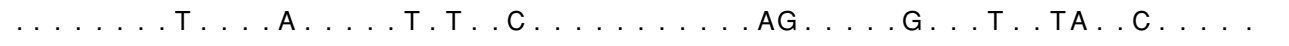 \\
\hline R.chensinensis (China) & 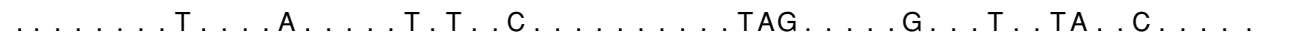 \\
\hline R.tsushimensis (Japan) & 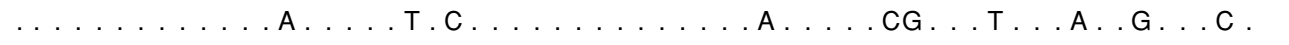 \\
\hline R.a.coreana (S.Korea) & 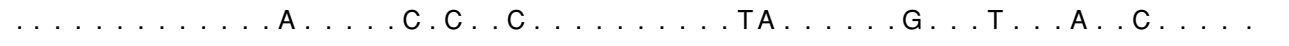 \\
\hline R.a.amurensis (China) & $\ldots \ldots$. . . . . . . T. C C . . . . TA . . . . A . C . . \\
\hline R.a.amurensis (Russia) & $\ldots \ldots \ldots$..... T.C.C. \\
\hline
\end{tabular}

R.catesbeiana

R.dybowskii (N.Korea) R.dybowskii (S.Korea) R.huanrenensis (S.Korea) R.chensinensis (China) R.tsushimensis (Japan) R.a.coreana (S.Korea) R.a.amurensis (China) R.a.amurensis (Russia)

R.catesbeiana R.dybowskii (N.Korea) R.dybowskii (S.Korea) R.huanrenensis (S.Korea) R.chensinensis (China) R.tsushimensis (Japan) R.a.coreana (S.Korea) R.a.amurensis (China) R.a.amurensis (Russia)
TATGAACCACAATTCTAAGAATCAATAAACTGATGTTTAATGATCCAATTTTTTGATCA A

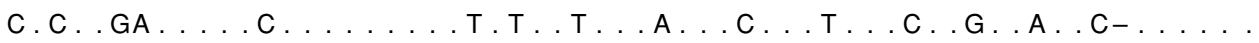

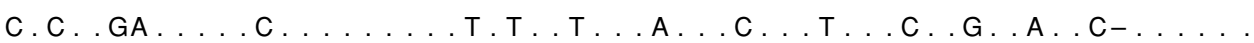

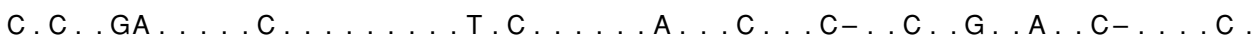

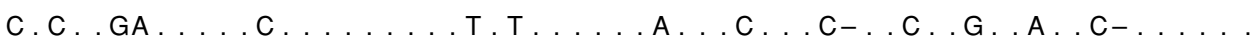

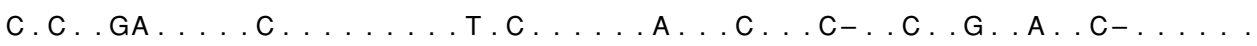

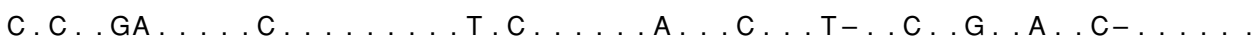

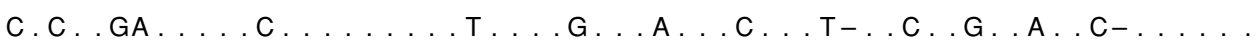

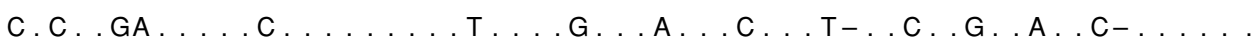

\section{1}

\section{CGAACCAAGTTACCCTGGGGATAACAGCGCAATCTACTTCAAGAGCTCCTATCG}

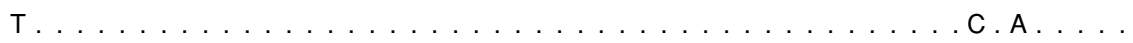

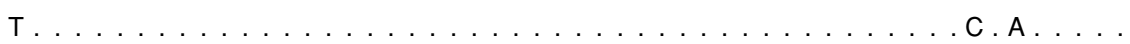

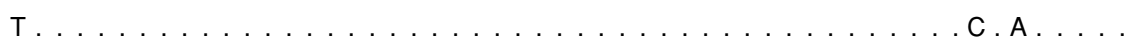

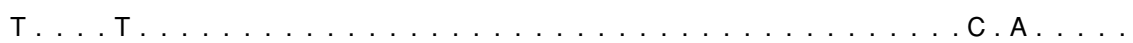

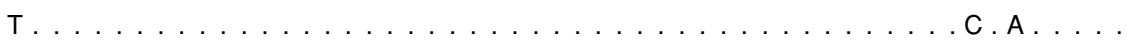

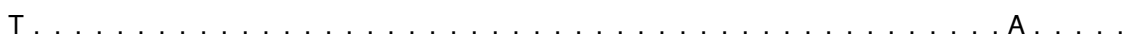

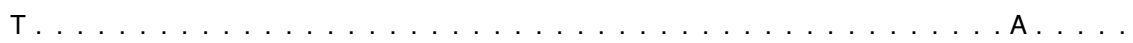

$\mathrm{T} \ldots \ldots \ldots \ldots \ldots \ldots \ldots \ldots \ldots \ldots \ldots \ldots \ldots \ldots \ldots$ 